\title{
Assessing the effect of band selection on accuracy of pansharpened imagery: application to young woody vegetation mapping
}

\author{
Emmanuel Fundisi and Solomon G. Tesfamichael \\ Department of Geography, Environmental Management and Energy Studies, University of \\ Johannesburg, South Africa \\ Email: fundisye@icloud.com; sgtesfamichael@uj.ac.za
}

DOI: http://dx.doi.org/10.4314/sajg.v7i2.2

\begin{abstract}
Expansion of woody vegetation has adverse effects on ecosystem services, and thus it is desirable to contain the problem at the early developmental stages. This can be aided by using high spatial resolution remotely-sensed data. The study investigated the effect of band selection during pansharpening on the ability to discriminate young woody vegetation from coexisting land cover types. Red-green-blue (RGB) spectral bands (30 m) of Landsat 8 imagery was pansharpened using the panchromatic band (15 $\mathrm{m}$ ) of the same image to improve spatial resolution. Near-infrared (NIR), shortwave-infrared 1 (SWIR1) and shortwave-infrared 2 (SWIR2), bands were used respectively as the fourth spectral band during pansharpening, resulting in three pansharpened images. Unsupervised classification was performed on each pansharpened image as well as nonpansharpened multispectral image. The overall accuracies of classification derived from the pansharpened image was higher (87\% - 89\%) than that derived from the non-pansharpened multispectral image (83\%). The study shows that band selection did not affect the classification accuracy of woody vegetation significantly. In addition, the study shows the potential of pansharpened Landsat data in detecting woody vegetation encroachment at the early growth stage.
\end{abstract}

Keywords: Young woody vegetation, Landsat, pansharpening, unsupervised classification

\section{Introduction}

The imbalance in the natural ecosystem between herbaceous plants and woody vegetation poses a threat to the natural environment (Archer et al., 2017). It is therefore vital to monitor the status of grass-woody vegetation composition at the early stages of wood encroachment in order to maintain a healthy balance in such ecosystems. Traditional methods of quantifying woody vegetation involve field inventories and are generally inefficient, expensive and time consuming particularly for covering large spatial extents. Remote sensing overcomes these drawbacks and has been exploited widely for woody vegetation assessment (e.g., Ghebrezgabher et al., 2016; Rajendran et al., 2016; Amarnath et al., 2017; Dibs et al., 2017).

A number of studies integrated coarse resolution remotely-sensed data such as Moderate Resolution Imaging Spectroradiometer (MODIS) imagery and sparsely distributed field verification 
data to map woody vegetation (Mishra et al., 2015; Gill et al., 2017; Tian et al., 2017; Adami et al., 2018). Although such data offer a wide spatial coverage at short time intervals; they primarily capture information about spatially aggregated earth features. Young woody vegetation ecosystems common in new woody vegetation encroachment and secondary forest regeneration scenarios present challenges in the application of coarse resolution data due to confusion in spectral characteristics with grass or bare land (Odindi et al., 2016; Rautiainen et al., 2018). There is therefore the need to utilize a better resolution remote sensing to represent localised variabilities. Although high spatial resolution data such as QuickBird, RapidEye and Worldview provide improved capability for land cover mapping (Oelofse et al., 2015; Robinson et al., 2016; Madonsela et al., 2017), most of them are commercial and thus are expensive for routine and large-scale monitoring purposes.

In contrast, Landsat imagery is a typical example of remotely-sensed data that have been widely used for moderate resolution land cover assessment, including woody vegetation mapping and monitoring (Lwin, and Murayama, 2013; Symeonakis and Higginbottom, 2014; Gartzia et a., 2014; Gill et al., 2017; Huang et al., 2017; Skowno et al., 2017; Rahman et al., 2018; Wang et al., 2018). Gumbi et al. (2013), for example, assessed woody vegetation dynamics using Landsat in acacia dominated semi-arid environment with only 30 samples measuring $20 \mathrm{~m}$ x $50 \mathrm{~m}$ to represent a 700 km2 spatial area. Mirik and Ansley (2012) reported an overestimation of honey mesquite canopy cover derived from Landsat data and 25 field sample plots each measuring $200 \mathrm{~m}$ x $200 \mathrm{~m}$. Mancino et al. (2013) assessed woody vegetation expansion using Landsat data by dividing the entire area into $25 \mathrm{~km} \times 25 \mathrm{~km}$ quadrants in which a total of 200 random sample points were established. The sampling strategy which resulted in an average of four reference points per quadrant indicates a high degree of generalization at the expense of local variations. Such sampling strategies are not suitable to identify woody vegetation encroachment at the early growth stages. This study investigated the effect of band selection during pansharpening on the ability to discriminate woody vegetation from coexisting land cover types in a semi-arid environment dominated by young acacia species. Unlike broadleaved vegetation, acacia has relatively low foliage that can lead to spectral signatures similar to background land cover types, particularly when it is at young developmental stage (Madonsela et al., 2017). Moreover, the low spatial occupancy at young stage due to the often-single stem structure (Zhu and Liu, 2014) implies that its reflectance properties can be contaminated by the surrounding land cover types. This study therefore provides an important indication on the performance of readily available moderate-resolution remotely sensed data to characterize vegetation properties at the scale of the data.

\section{Methods}

\subsection{Study area}

The study area is located in the Eastern Cape Province, South Africa (Figure 1). The area was delineated specifically for this study close to human settlements, which seemingly influenced woody plant growth through anthropogenic activities. Elevation of the study area varies between $246 \mathrm{~m}$ to 
$1419 \mathrm{~m}$ above mean sea level. The temperature varies between $10^{\circ} \mathrm{C}$ and $27^{\circ} \mathrm{C}$ averaging at $12^{\circ} \mathrm{C}$. Monthly precipitation ranges between 66 and $77 \mathrm{~mm}$, with high rainfall between November and March. The study area hosts four broad biomes: savanna, grassland, thicket (Mucina and Rutherford, 2011).

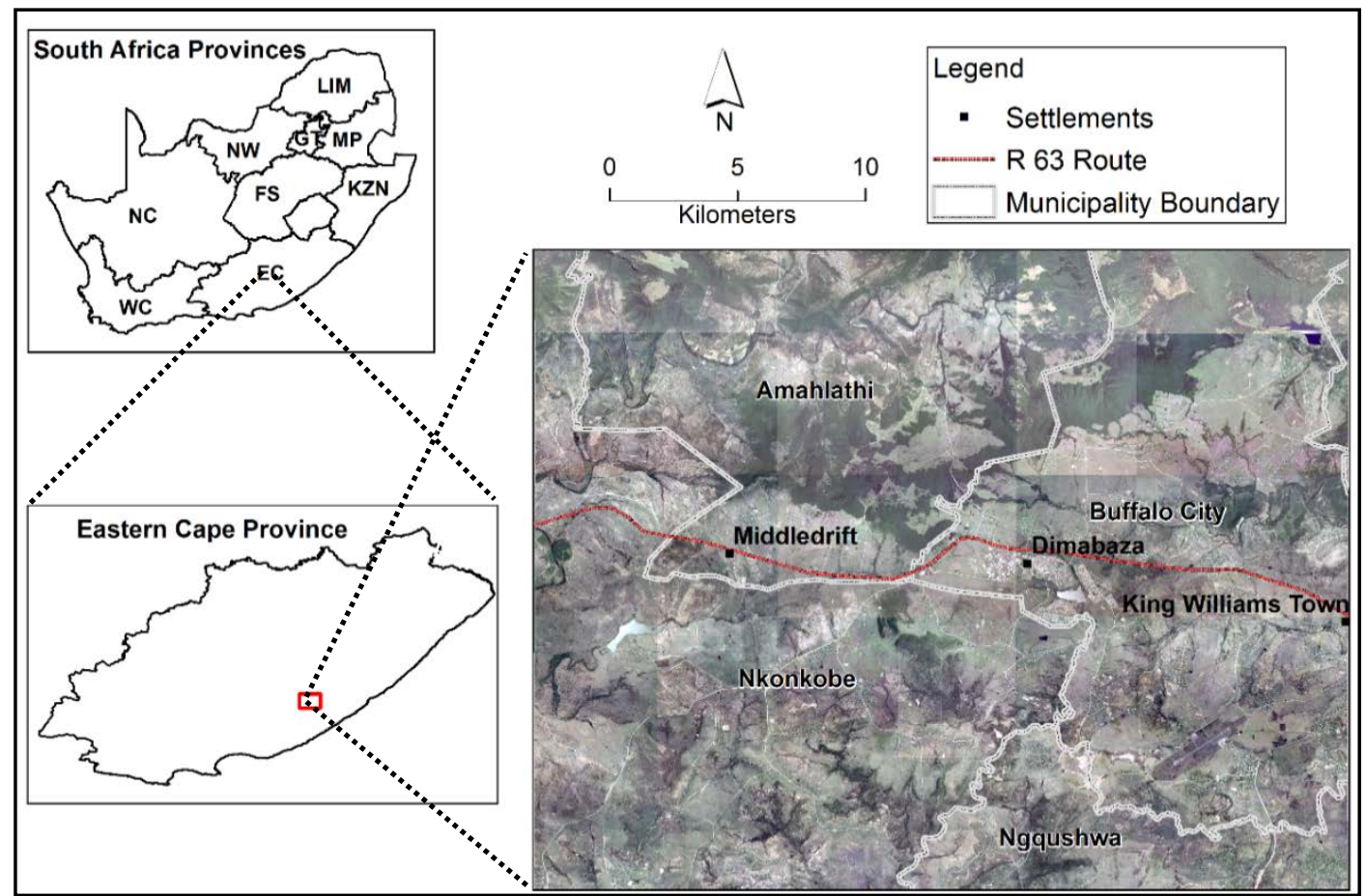

Figure 1. Study area within Eastern Cape, South Africa. The background image is a high spatial resolution aerial photograph obtained from the National Geo-Spatial Information (NGI), Department of Rural Development and Land Reform (DRLR), South Africa

\subsection{Reference Data}

Orthorectified high spatial resolution aerial photographs obtained from NGI, DRDLR, South Africa, were used as a source of reference data for the study. The photographs were acquired during the rainy season of February 2014. Remotely sensed data acquired during a rainy season captures vegetation properties at relatively high photosynthetic activities (Dorigo et al., 2012). A spatial resolution of $0.5 \mathrm{~m}$ of the aerial photographs was deemed sufficient to interpret features that can be used as reference data. Such data have been used successfully in other studies to either evaluate remote sensing interpretation or to train classification of remotely-sensed data (Mirik and Ansley, 2012; Symeonakis and Higginbottom, 2014; Mograbi et al., 2015).

Seven transects spaced at $5 \mathrm{~km}$ intervals were laid along the north-south direction of a main road (R 63) that links human settlements in the region (Figure 2a). On each transect, sampling sites were placed at $1 \mathrm{~km}$ interval on either side of the road for $10 \mathrm{~km}$, resulting in 20 sites per transect. In total, 140 sites were laid on all transects. A 60 m radius buffer was created around each site; this size was equivalent to 11-14 pixels of Landsat imagery. Having multiple pixels reduces interpretation errors due to pixel displacement (Sun et al., 2017). In each buffer, points were placed at $20 \mathrm{~m}$ x $20 \mathrm{~m}$ interval, 
resulting in 26 to 30 points per buffer (Figure 2b). This yielded a total of 3813 samples within the study area.

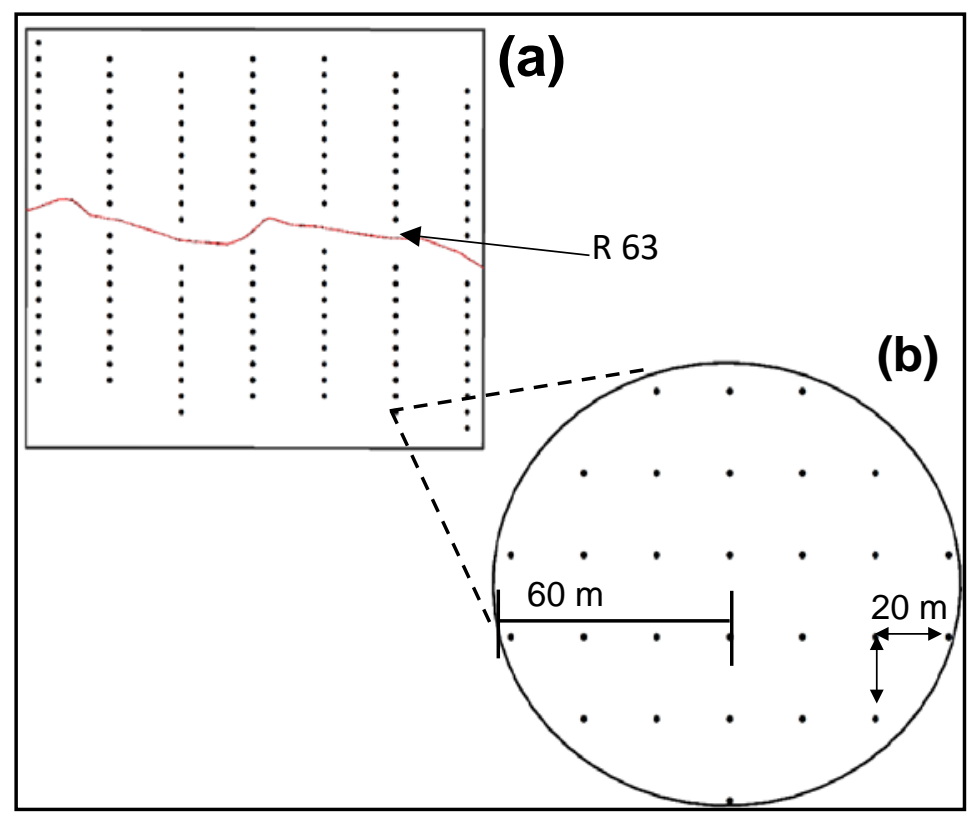

Figure 2. Map showing sampling layout of the study: (a) 140 points on either side of main road, and (b) $60 \mathrm{~m}$ radius buffer about each point used for land cover interpretation

The land cover type that each point falls on was recorded from the aerial photographs. These land cover types were approximated according to Thompson (1996) that standardised land cover types for the purpose of remote sensing interpretation. The standard classification system was modified by merging structurally similar land cover types in order to suit the land cover types of the study area. Woodland refers to all woodland areas with greater than $10 \%$ tree canopy cover and essentially indigenous trees growing under natural conditions. Grassland was categorised as unimproved and improved; unimproved grassland refers to indigenous grass species growing under natural conditions; improved grassland denotes to planted grassland either indigenous or exotic species. Bare land includes natural areas of exposed soil with little vegetation. Water bodies refers to areas of generally open water, either natural or man-made water bodies and this was classified under water (Thompson, 1996).

\subsection{Pansharpening}

Landsat 8 imagery acquired in February 2014 was downloaded from the United States Geological Survey (USGS) (http://earthexplorer.usgs.gov/). Spatial resolution of Landsat can be enhanced using algorithms which combine spatially detailed structure of a high-resolution panchromatic image with lower resolution bands of the same imagery or another acquired preferably during the same time (Lwin and Murayama, 2013). Various pansharpening methods such as Brovey transform-based fusion (Gillespie et al., 1987), Gram-Schmidt (Laben and Brower, 2000) and Intensity Hue Saturation (Carper et al., 1990) have been used to produce spatially enhanced multispectral images. The current study utilised the Gram-Schmidt algorithm which maximizes image sharpness, minimizes colour 
distortion and uses more than three bands (Laben and Brower, 2000). This technique was utilised for vegetation mapping previously by, for instance, Okin et al (2013) and Rapinel et al (2014) who showed that the spectral characteristics of the lower spatial resolution multispectral data were preserved in the resultant pansharpened image. Pansharpening was implemented in this study as follows. Blue, green, red and near infrared (NIR) were combined to create a multispectral image, and subsequently pansharpened using the $15 \mathrm{~m}$ panchromatic image. This process was repeated by replacing the near infrared colour with shortwave infrared 1 (SWIR1) and shortwave infrared 2 (SWIR2), resulting in a total of three pansharpened images. The study also used a multispectral image of all the visible and infrared bands to see how pansharpened image in general compares with nonpansharpened image.

\subsection{Image classification}

A number of classification techniques are available to the remote sensing community. They vary from parametric to non-parametric as well as hard and soft (fuzzy) classification (Im and Jensen, 2005). These techniques include, among others, supervised (Winston, 1975), unsupervised (Tou and Gonzalez, 1974), artificial neural networks (McClellan et al, 1989), support vector machines (Cortes and Vapnik, 1995) and Random Forest (Breiman, 2001). An unsupervised classification approach was adopted for this study because it allows spectral clusters to be identified with a high degree of objectivity (Lillesand et al, 2008) and this approach was used to classify both the non-pansharpened and the pansharpened images. Unsupervised classifiers involve algorithms that inspect the unknown pixels in an image and aggregate them into a number of classes based on the natural groupings or clusters present in the image values. The ISODATA (Iterative Self Organizing Data Analysis Technique) method starts by calculating class means evenly distributed in the data space, then iteratively groups the remaining pixels using minimum distance techniques (Im and Jensen, 2005). Each iteration recalculates means and reclassifies pixels with respect to the new means. This process continues until the percentage of pixels that change classes during an iteration is less than the change threshold or the maximum number of iterations is reached (Im and Jensen, 2005). This classification approach has two main advantages; (1) it produces spectral clusters with a high degree of objectivity, and (2) it does not require in-depth, prior knowledge about the land cover types present in the area. A fairly large number of classes can be generated and subsequently reduced to fewer classes depending on the variability present in the area of interest (Lillesand et al., 2008). In this study, eight classes were created and subsequently reduced to four classes (woodland, grassland, bare land and water) by merging structurally similar land cover types through interpretations. A similar approach was followed in classifying each of the pansharpened images. Different band combinations such as false colour combination (infrared, red and green) and natural colour combination (red, green and blue) were used as reference in the interpretation process of the classified data. Such interpretation is customary within the remote sensing community for land cover classification purposes (e.g. Mirik and Ansley, 2012; Nguyen et al., 2015). The interpretation involved visual assessment of at least three largest and contiguous coverage of each class. Visualising large features enhances the reliability of interpretation, compared to interpreting few pixels of a class. 


\subsection{Accuracy assessment}

Accuracies of classes derived from the multispectral and pansharpened data were assessed by comparing with reference data derived from the high spatial resolution orthorectified photographs. All accuracies were assessed using the total number of points which were established inside the buffered sample plots. An error matrix which is a standard classification assessment method was used to evaluate each classified product (Congalton and Green, 2009). The method uses statistics such as overall accuracy, producer's accuracy, and user's accuracies. Kappa statistics was also used to evaluate the quality of classified data (Story and Congalton, 1986). Although accuracies of all four land cover types (woodland, grassland, bare land and water) were computed, much emphasis was placed on woody vegetation, in line with the aim of the study.

\section{Results}

Overall accuracies were better using pansharpened images (87-89\%; kappa: 0.80-0.81) than those classified using the non-pansharpened image (83\%; 0.75) (Figure 3). A comparison among the pansharpened images showed marginally superior performance by pansharpening using the NIR followed by the SWIR2 and SWIR1, respectively. Figure 4 compares per class classification accuracies. Woodland and grassland had comparable producer's accuracies in all the pansharpening approaches (91-93\%). Although these accuracies are considered high, it is important to recognize the sources of producer's accuracies by looking at confusions in Table 2. Woodland was mostly confused with grassland, while grassland was confused mostly with both woodland and bare land. Pansharpening using NIR yielded the lowest confusion between grassland and woodland $((113 / 1333) * 100=7 \%)$, while non-pansharpened and pansharpening with SWIR1 having the highest omission of woodland due to misallocation to grassland ( 9\%). Reciprocally, the omission of grassland due to misallocation to woodland was less when the pansharpening was created using NIR $((59 / 1294) * 100=4 \%)$ and SWIR1 (4\%) than for the non-pansharpened (6\%) and pansharpening using SWIR2 (6\%) (Table 2). The classification resulted in less number of woodland classes (1269-1299) than the actual number of classes (1333) (Table 2). In comparison, bare land and grassland generated considerably higher number of classes than the actual number on the ground, respectively.

The user's accuracy (that also measures commission error) of woodland varied between 94 and 96\% (Figure 4). Looking at Table 2, most of the confusion that contributed to loss in user's accuracy was due to misplaced allocation of grassland to the class. For example, the classification that utilized the NIR in the pansharpening resulted in 47 grasslands wrongly allocated to woodland. Grassland class had fairly low user's accuracies; the main source of this inaccuracy is attributed to large number of bare land and woodland classes wrongly assigned to the class. 


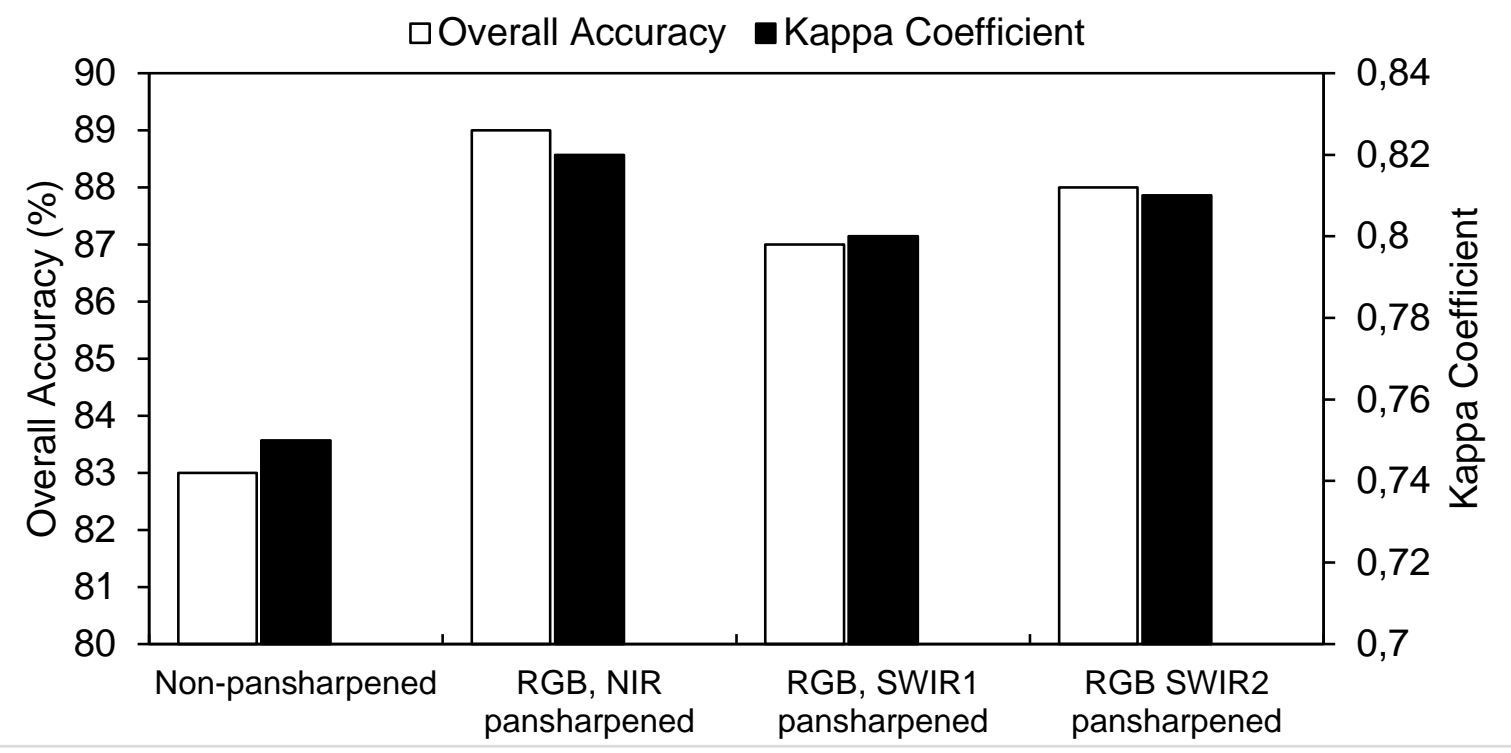

Figure 3. Overall accuracy and Kappa coefficient for the different pansharpening approaches

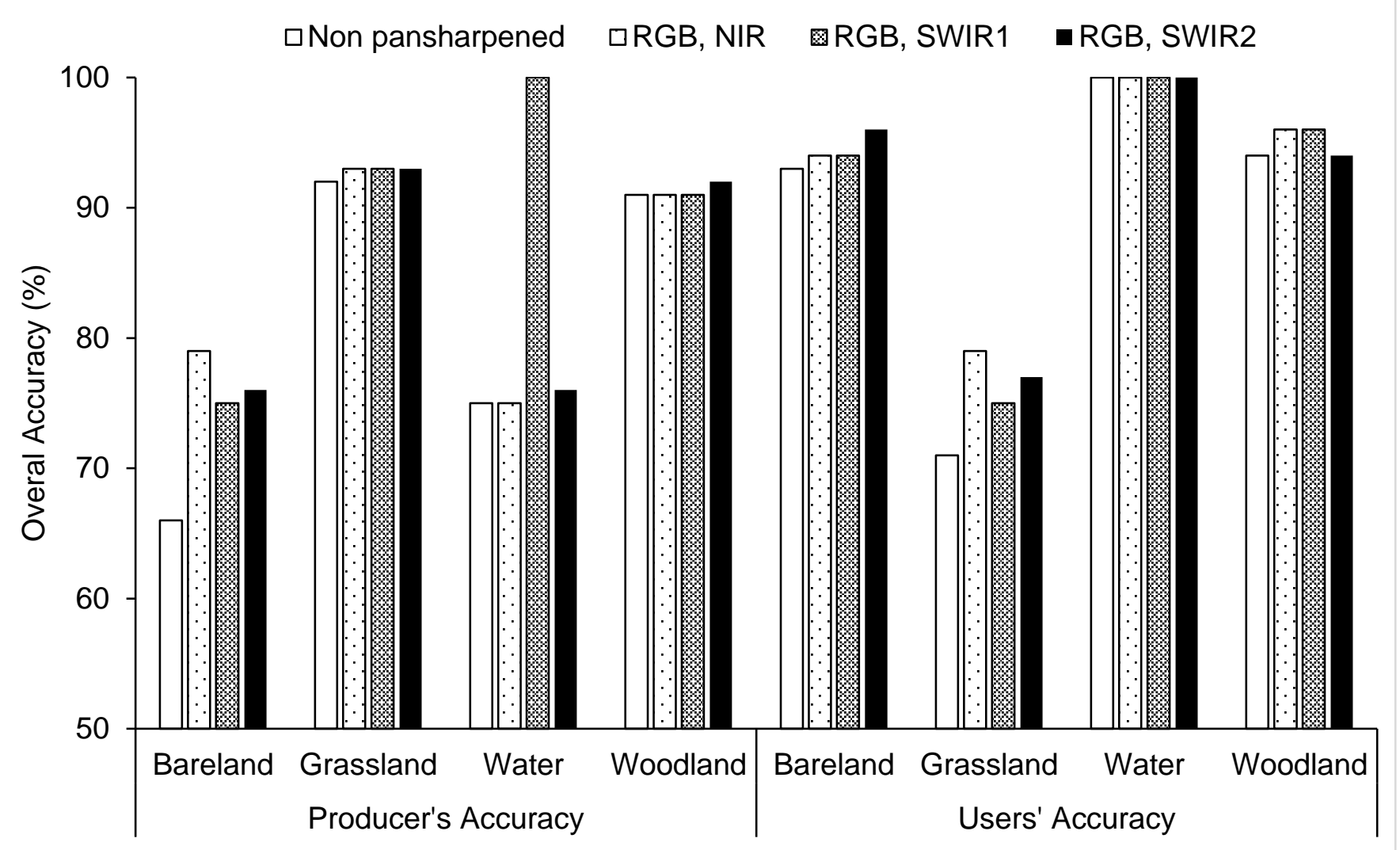

Figure 4. Producer's and User's accuracies of the different pansharpening approaches: (a) nonpansharpened, (b) RGB, NIR-pansharpened, (c) RGB, SWIR1-pansharpened, (d) RGB, SWIR2pansharpened 
Table 2. Accuracies of the non-pansharpened multispectral based classification and pansharpened based classification merging RGB bands NIR and SWIR bands

\begin{tabular}{|c|c|c|c|c|c|c|}
\hline \multicolumn{7}{|c|}{ Non-pansharpened multispectral image } \\
\hline \multirow{7}{*}{ 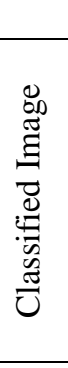 } & \multicolumn{6}{|c|}{ Reference Data } \\
\hline & & Bare land & Grassland & Water & Woodland & Total \\
\hline & Bare land & 773 & 48 & 3 & 5 & 829 \\
\hline & Grassland & 379 & 1187 & 2 & 103 & 1681 \\
\hline & Water & 0 & 0 & 15 & 0 & 15 \\
\hline & Woodland & 14 & 59 & 0 & 1235 & 1288 \\
\hline & Total & 1166 & 1294 & 20 & 1333 & 3813 \\
\hline \multicolumn{7}{|c|}{ Red, Blue, Green, NIR Pansharpened image } \\
\hline \multicolumn{7}{|c|}{ Reference Data } \\
\hline \multirow{6}{*}{ 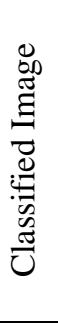 } & & Bare land & Grassland & Water & Woodland & Total \\
\hline & Bare land & 923 & 48 & 3 & 4 & 978 \\
\hline & Grassland & 234 & 1199 & 0 & 90 & 1523 \\
\hline & Water & 0 & 0 & 15 & 0 & 15 \\
\hline & Woodland & 9 & 47 & 2 & 1239 & 1297 \\
\hline & Total & 1166 & 1294 & 20 & 1333 & 3813 \\
\hline \multicolumn{7}{|c|}{ Red, Blue, Green, SWIR1 Pansharpened image } \\
\hline \multicolumn{7}{|c|}{ Reference Data } \\
\hline \multirow{6}{*}{ 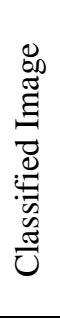 } & & Bare land & Grassland & Water & Woodland & Total \\
\hline & Bare land & 874 & 48 & 0 & 5 & 927 \\
\hline & Grassland & 285 & 1199 & 0 & 113 & 1597 \\
\hline & Water & 0 & 0 & 20 & 0 & 20 \\
\hline & Woodland & 34 & 47 & 0 & 1215 & 1269 \\
\hline & Total & 1166 & 1294 & 20 & 1333 & 3813 \\
\hline \multicolumn{7}{|c|}{ Red, Blue, Green, SWIR2 Pansharpened image } \\
\hline \multicolumn{7}{|c|}{ Reference Data } \\
\hline \multirow{6}{*}{ 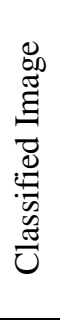 } & & Bare land & Grassland & Water & Woodland & Total \\
\hline & Bare land & 890 & 30 & 3 & 5 & 928 \\
\hline & Grassland & 263 & 1205 & 2 & 101 & 1571 \\
\hline & Water & 0 & 0 & 15 & 0 & 15 \\
\hline & Woodland & 13 & 59 & 0 & 1227 & 1299 \\
\hline & Total & 1166 & 1294 & 20 & 1333 & 3813 \\
\hline
\end{tabular}

A closer look at the performances of classifications using the non-pansharpened and the three pansharpened images in discriminating woodland from other classes is illustrated in Figure 5. Note that the figure illustrates an area dominated mainly by woodland and grassland, since accuracy of the former was influenced predominantly by the latter (Table 3). Figure 5(a) represents an extract from aerial image (reference data) focussing on a mixture of grassland, young woodland and limited bare land covers, while 5(b), (c), (d) and (e) show classes of the same extract derived from nonpansharpened, pansharpened using RGB-NIR, RGB-SWIR1, and RGB-SWIR2 bands, respectively. The non-pansharpened image resulted in overestimation of woodland cover. Figure 5(c) shows better 
representation of woodland and compared to Figure 5(d) and (e) illustrates confusion between grassland and woodland class on the top left of the figures.

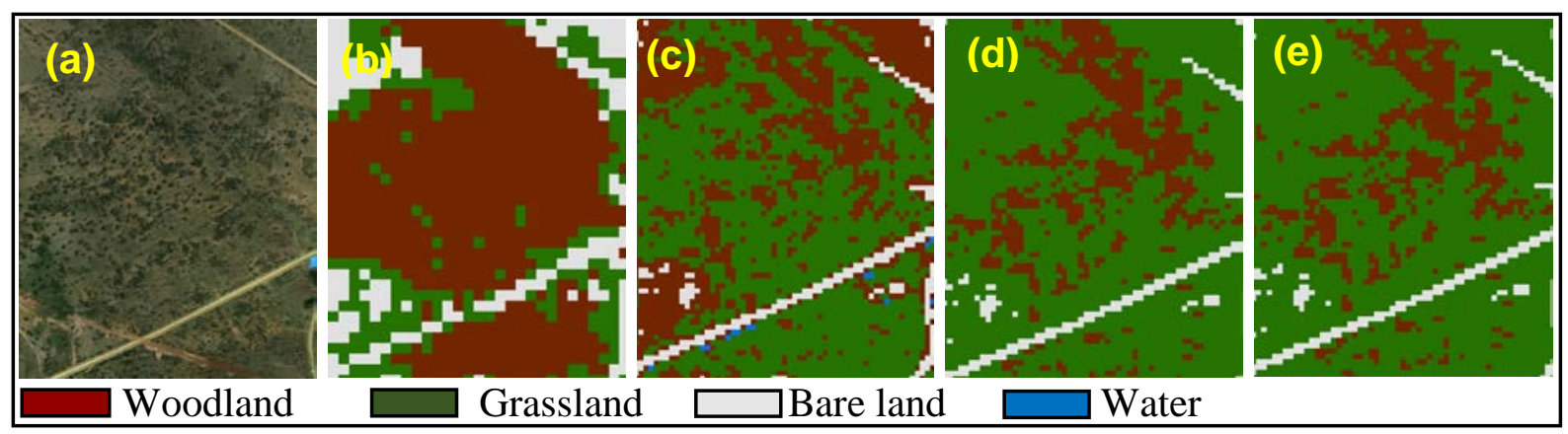

Figure 5: Illustration of the performance of the different pansharpening approaches: (a) aerial image

(b) non-pansharpened image (b) RGB, NIR-pansharpened, (c) RGB, SWIR1-pansharpened, (d)

RGB, SWIR2-pansharpened

\section{Discussion}

The study assessed the effect of band selection in pansharpening on classifying young woody vegetation and other land cover types. Classifications using pansharpened images performed better than using the non-pansharpened image. The increase in accuracy is attributed to the improvement in the spatial resolution of the non-pansharpened multispectral Landsat imagery in addition to its spectral resolution. Improved spatial resolution enables clear representation of features on the images resulting in more accurate image classification (Johnson et al., 2013). This is consistent with various studies that applied pansharpening technique in vegetation classification purposes (e.g., Johnson et al., 2013; Lin et al., 2015; Palubinskas, 2015). Johnson et al (2013), for example, demonstrated that pansharpened RGB and NIR Landsat imagery enabled easy visual identification of pine and oak trees. In another study, Johnson (2014) assessed the effects of pansharpening in monitoring vegetation patches and concluded that pansharpening improved classification accuracy due to feature enhancement of vegetation cover.

The Individual accuracies such as producer's and user's accuracy show that there was confusion between woody vegetation and grassland. Accuracy of discriminating young woody vegetation using non-pansharpened multispectral image was partly affected by the fact that it was misinterpreted as grassland. The confusion between these two (woodland and grassland) classes is expected particularly during the rainy season when grasses grow to greater heights depicting high chlorophyll levels (greenness) similar to young woody plants. Hudak and Wiseman (1998) characterised woody vegetation expansion in South Africa, in which they showed that multispectral Landsat image is capable of detecting large land cover types such as forest stands while the image was rather weak in discriminating woody vegetation from grassland. It is also important to mention that, confusions in classes were also caused due to utilisation of point-based analyses of the classified image followed in this study. Interpretation of land cover type at a point may not represent the land cover type occupied within the extent of a pixel and a neighbourhood of pixels. This is particularly true for a piece of land with mixed land cover types. For example, a point in the reference data obtained from Google Earth 
may indicate a grassland located among woody plants while a pixel in the same area may have reflectance value dominated by woody plants and thus is classified as woodland.

Differences in accuracies among the classes created from pansharpened images were marginal; however, the pansharpened image derived from RGB and NIR band returned slightly better overall classification accuracy compared to the others. The output from the results could be to some extent explained by the fact that NIR band is sensitive mainly to biomass content, while the SWIR bands are influenced by soil moisture content more than NIR is (Campbell and Wayne, 2011; Dorigo et al., 2012). Similar results were observed in a study by Kokaly and Skidmore (2015) who analysed absorption and reflective capabilities of vegetation canopy using remotely-sensed data.

\section{Conclusion}

The study presented in this paper investigated the effect of band selection during pansharpening process in discriminating young woody vegetation from other land cover types. All pansharpening that utilized NIR, SWIR1 and SWIR2, respectively, improved discrimination of woody vegetation from other land cover types, compared to the non-pansharpened image. However, there was limited difference in overall classification accuracies among the three pansharpened images. Overall, the study showed the potential of pansharpened Landsat data to identify woody vegetation encroachment at the young stage; such capability will certainly assist in the monitoring and management of grasswood dynamics that are under threat from the changing climate conditions and as a result of anthropogenic pressures (Zhu and Liu, 2014). Although the accuracy of results obtained in this study were promising, it is important to note the effect of sampling unit on accuracy. This study used sample points as a unit of interpretation and class definition for the reference data against which results obtained from remote sensing were compared. We believe that increasing the unit of interpretation to a plot-level (area based) would improve the reliability of the results. This study also envisages the use of better remotely-sensed data and analysis techniques will improve accuracies of identifying woody vegetation encroachment.

\section{Acknowledgements}

This research was funded through student scholarship by the National Research Foundation scholarship (NRF, South Africa) as well as various support systems from the University of Johannesburg, South Africa.

\section{Disclosure statement}

No potential conflict of interest was reported by the authors. 


\section{References}

Adami, M., Bernardes, S., Arai, E., Freitas, R. M., Shimabukuro, Y. E., Espírito-Santo, F. D., Anderson, L. O., 2018. Seasonality of vegetation types of South America depicted by moderate resolution imaging spectroradiometer (MODIS) time series. International Journal of Applied Earth Observation and Geoinformation. 69: 148-163.

Amarnath, G., Babar, S., and Murthy, M. S. R., 2017. Evaluating MODIS-vegetation continuous field products to assess tree cover change and forest fragmentation in India-A multi-scale satellite remote sensing approach. The Egyptian Journal of Remote Sensing and Space Science. 20: 157-168.

Archer, S. R., Andersen, E. M., Predick, K. I., Schwinning, S., Steidl, R. J., and Woods, S. R., 2017. Woody plant encroachment: causes and consequences. In Rangeland Systems. pp. 25-84.

Archer, S., Woods, S. and Howery, L. D., 2009. Grasslands or shrubland? Tipping the balance. Backyards and beyond, rural living in Arizona. University of Arizona Cooperative. Extension Service. 3: 3-4.

Brandt, M., Hiernaux, P., Tagesson, T., Verger, A., Rasmussen, K., Diouf, A. A., and Fensholt, R., 2016. Woody plant cover estimation in drylands from Earth Observation based seasonal metrics. Remote Sensing of Environment. 172: 28-38.

Breiman, L. (2001). Random forests. Machine Learning. 45: 5-32.

Campbell, J. B. and Wynne, R. H., 2011. Introduction to remote sensing. 5th Ed. London. Taylor and Francis. pp. 117-121.

Carper, W. J., Lillesand, T. M. and Kiefer, R. W., 1990. The use of intensity-hue-saturation transformations for merging SPOT panchromatic and multispectral image data. Photogrammetric engineering and Remote Sensing. 56: 459-467.

Congalton, R. G. and Green, K., 2009. Assessing the accuracy of remotely sensed data: Principles and practices. 2nd Ed. Boca Raton. Florida. CRC Press. p. 210.

Cortes, C. and Vapnik, V. N. (1995). Support Vector networks. Machine Learning. 20: 20-35.

Dibs, H., Idrees, M. O., and Alsalhin, G. B. A., 2017. Hierarchical classification approach for mapping rubber tree growth using per-pixel and object-oriented classifiers with SPOT-5 imagery. The Egyptian Journal of Remote Sensing and Space Science. 20: 21-30.

Dorigo, W., Lucieer, A., Podobnikar, T. and Carni, A., 2012. Mapping invasive Fallopia japonica by combined spectral, spatial and temporal analysis of digital orthophotos. International Journal of Applied Earth Observation and Geoinformation. 19: 185-195.

Gartzia, M., Alados C. L. and Perez-Cabello, F., 2014. Assessment of the effects of biophysical and anthropogenic factors on woody plant encroachment in dense and sparse mountain grasslands based on remote sensing data. Progress in Physical Geography. 38: 201-217.

Gaughan, A. E., Holdo, R. M., and Anderson, T. M., 2013. Using short-term MODIS time-series to quantify tree cover in a highly heterogeneous African savanna. International Journal of Remote Sensing.19: $6865-6882$.

Ghebrezgabher, M. G., Yang, T., Yang, X., Wang, X., and Khan, M., 2016. Extracting and analyzing forest and woodland cover change in Eritrea based on landsat data using supervised classification. The Egyptian Journal of Remote Sensing and Space Science. 19: 37-47.

Gill, T., Johansen, K., Phinn, S., Trevithick, R., Scarth, P., and Armston, J., 2017. A method for mapping Australian woody vegetation cover by linking continental-scale field data and long-term Landsat time series. International Journal of Remote Sensing. 38: 679-705.

Gillespie, A.R., Kahle, A.B., and Walker, R.E., 1987. Color enhancement of highly correlated images. II. channel ratio and 'chromaticity' transformation techniques. Remote Sensing of Environment. 22: 343-365. 
Gumbi, A., Sibanda, Q. E., Macherera, M., Moyo, L. and Kupika, O. L., 2013. Assessment of woody vegetation cover changes in Bulawayo over the period 1990-2010. Arboricultural Journal: The International Journal of Urban Forestry. 35: 220-235.

Huang, H., Chen, Y., Clinton, N., Wang, J., Wang, X., Liu, C., and Zhu, Z., 2017. Mapping major land cover dynamics in Beijing using all Landsat images in Google Earth Engine. Remote Sensing of Environment. 202: $166-176$.

Hudak, A. T. and Wessman, C. A., 1998. Textural analysis of historical aerial photography to characterize woody plant encroachment in South African savanna. Remote Sensing of Environment. 66: 317-330.

Im, J. and Jensen, J. R., 2005. A change detection model based on neighbourhood correlation image analysis and decision tree classification. Remote Sensing of Environment. 993: 26-34.

Johnson, B. A., Tateishi, R. and Hoan, N. T., 2013. A hybrid pan-sharpening approach and multiscale objectbased image analysis for mapping diseased pine and oak trees. International Journal of Remote Sensing. 34: 6969-6984.

Johnson, B., 2014. Effects of pan-sharpening on vegetation indices. ISPRS International Journal of GeoInformation. 2: 507-522.

Kokaly, R. F. and Skidmore, A. K., 2015. Plant phenolics and absorption features in vegetation reflectance spectra near $1.66 \mu \mathrm{m}$. International Journal of Applied Earth Observation and Geoinformation. 43: 55-83.

Laben, C. A. and Brower, B.V., 2000. Process for enhancing the spatial resolution of multispectral imagery using pan-sharpening. Eastman Kodak Company, U.S. Patent No. 6,011,875.

Lillesand, T. M., Kiefer, R. W. and Chipman, J., 2008. Remote sensing and image interpretation. 6th Ed. New York. John Wiley and Sons.

Lin, C., Wu, C., Tsogt, C., Ouyang, K. and Ouyang. Y. C., 2015. Effects of atmospheric correction and pansharpening on LULC classification accuracy using WorldView-2 imagery. Information Processing in Agriculture. 2: 25-30.

Lwin, K. K. and Murayama, Y., 2013. Evaluation of land cover classification based on multispectral versus pan-sharpened Landsat ETM+ imagery. GI Science and Remote Sensing. 50: 458-472.

Madonsela, S., Cho, M. A., Mathieu, R., Mutanga, O., Ramoelo, A., Kaszta, Z., and Wolff, E., 2017. Multiphenology WorldView-2 imagery improves remote sensing of savannah tree species. International Journal of Applied Earth Observation and Geoinformation. 58: 65-73.

Mancino, G., Nole, A., Ripullone, F. and Ferrara, A., 2013. Landsat TM imagery and NDVI differencing to detect vegetation change: assessing natural forest expansion in Basilicata, Southern Italy. IForest. 7: $75-84$.

McClellan, G. E., Dewitt, R. N., Hemmer, T. H., Matheson, L. N. and Moe, G. O. (1989). Multispectral image processing with a three layer back propagation network. Proceeding, 1989 International Joint Conference on Neutral Networks. 3: 151-153.

Mirik, M. and Ansley, R. J., 2012. Comparison of ground-measured and image-classified Honey Mesquite (Prosopis Glandulosa) canopy cover in Texas. Rangeland Ecology and Management. 65: 85-95.

Mishra, N. B., Crews, K. A., Neeti, N., Meyer, T., and Young, K. R., 2015. MODIS derived vegetation greenness trends in African savanna: deconstructing and localizing the role of changing moisture availability, fire regime and anthropogenic impact. Remote Sensing of Environment. 169: 192-204.

Mograbi, P. J., Erasmus, B. F. N., Witkowski, E. T. F., Asner, G. P., Wessels, K. J. and Mathieu, R., 2015. Biomass increases go under cover. Woody vegetation dynamics in South African Rangelands. PLOS ONE. 10: $1-21$.

Mucina, L. and Rutherford, M. C. (Eds)., 2011. The vegetation of South Africa, Lesotho and Swaziland. Strelitzia 19. South African National Biodiversity Institute. Pretoria. 
Nguyen, C, H., Jung, J., Lee, J., Choi, S., Hong, S. and Heo, J., 2015. Optimal atmospheric correction for above-ground forest biomass estimation with the ETM+ Remote Sensor. Journal of Remote Sensing. 15: 18865-18886.

Odindi, J., Mutanga, O., Rouget, M. and Hlanguza, N., 2016. Mapping alien and indigenous vegetation in the KwaZulu-Natal Sandstone Sourveld using remotely sensed data. Bothalia-African Biodiversity and Conservation, 46: 1-9.

Oelofse, M., Birch-Thomsen, T., Magid, J., de Neergaard, A., van Deventer, R., Bruun, S. and Hill, T., 2015. The impact of black wattle encroachment of indigenous grasslands on soil carbon, Eastern Cape, South Africa. Biological Invasion. 18:445-456

Okin, G. S., Clarke, K. D. and Lewis, M. M., 2013. Comparison of methods for estimation of absolute vegetation and soil fractional cover using MODIS normalized BRDF-adjusted reflectance data. Remote Sensing of Environment. 130: 266-279.

Palubinskas, G., 2015. Joint quality measure for evaluation of pan-sharpening accuracy. Remote Sensing Journal. 7: 9292-9310.

Rahman, M. M., Islam, M. S., and Pramanik, M. A. T., 2018. Monitoring of changes in woodlots outside forests by multi-temporal Landsat imagery. iForest-Biogeosciences and Forestry.11: p. 162.

Rajendran, S., Al-Sayigh, A. R., and Al-Awadhi, T., 2016. Vegetation analysis study in and around Sultan Qaboos University, Oman, using Geoeye-1 satellite data. The Egyptian Journal of Remote Sensing and Space Science. 19: 297-311.

Rapinel, S., Clément, B., Magnanon, S., Sellin, V. and Hubert-Moy, L., 2014. Identification and mapping of natural vegetation on a coastal site using a Worldview-2 satellite image. Journal of Environmental Management. 144: 236-246.

Rautiainen, M., Lukes, P., Homolovs, L., Hovi, A., Pisek, J., and Mottus, M., 2018. Spectral Properties of Coniferous Forests: A Review of In Situ and Laboratory Measurements. Remote Sensing. 10: p. 207.

Robinson, T. P., Wardell-Johnson, G. W., Pracilio, G., Brown, C., Corner, R., and Van Klinken, R. D., 2016. Testing the discrimination and detection limits of WorldView-2 imagery on a challenging invasive plant target. International Journal of Applied Earth Observation and Geoinformation. 44: 23-30.

Skowno, A. L., Thompson, M. W., Hiestermann, J., Ripley, B., West, A. G., and Bond, W. J., 2017. Woodland expansion in South African grassy biomes based on satellite observations (1990-2013): general patterns and potential drivers. Global change biology. 23: 2358-2369.

Story, M. and Congalton, R., 1986. Accuracy assessment: a user's perspective. Photogrammetry Engineering and Remote Sensing. 52: 397-399.

Sun, P., Congalton, R. G., Grybas, H., and Pan, Y., 2017. The Impact of Mapping Error on the Performance of Upscaling Agricultural Maps. Remote Sensing. 9: 901.

Symeonakis, E. and Higginbottom, T., 2014. Bush encroachment monitoring using multi-temporal Landsat data and random forests. The International Archives of Photogrammetry, Remote Sensing and Spatial Information Sciences. 2: 29-35.

Thompson, M., 1996. A standard land cover classification scheme for remote sensing applications in South Africa. South African Journal of Science. 92: 1-9.

Tian, F., Brandt, M., Liu, Y. Y., Rasmussen, K., and Fensholt, R., 2017. Mapping gains and losses in woody vegetation across global tropical drylands. Global change biology. 23: 1748-1760.

Tou, J. T. and Gonzalez, R. C. (1974). Pattern recognition principles. Volume 7 of applied mathematics and computation. Cornell University. Addison-Wesley Publishing Company. p. 377.

Tsalyuk, M., Kelly, M. and Getz, W. M., 2017. Improving the prediction of African savanna vegetation variables using time series of MODIS products. ISPRS Journal of Photogrammetry and Remote Sensing. 131: 77-91. 
South African Journal of Geomatics, Vol. 7. No. 2, AfricaGEO 2018 Special Edition, September 2018

Wang, J., Xiao, X., Qin, Y., Doughty, R. B., Dong, J., and Zou, Z., 2018. Characterizing the encroachment of juniper forests into sub-humid and semi-arid prairies from 1984 to 2010 using PALSAR and Landsat data. Remote Sensing of Environment. 205: 166-179.

Winston, P. H. (1975). Learning structural descriptions from examples. In Winston P. H. (Ed). The psychology of computer vision. New York. McGraw-Hill.

Zhu, X. and Liu, D., 2014. Accurate mapping of forest types using dense seasonal Landsat time-series. ISPRS Journal of Photogrammetry and Remote Sensing. 96: 1-11. 